\title{
Solar Variation and the Weather
}

\section{By Dr. C. G. Abbot, Smithsonian Institution}

$\mathrm{W}$ HILE he was visiting the United States at the end of last year, Sir Richard Gregory invited me to contribute to NATuRE a general review of the results of the long campaign of the Smithsonian Institution on the variation of the sun, which was instituted by the late secretary, S. P. Langley. Thus far it has accomplished about 40,000 measurements of the solar constant of radiation, involving observations filling about 10,000 days, besides numerous and interesting side researches. A more detailed account of results is expected to appear in the April issue of the Quarterly Journal of the Royal Meteorological Society.

In 1903 , by what now seems only a coincidence, a large drop occurred in our measurements at Washington of the solar constant of radiation, and simultaneously a considerable fall from mean temperature occurred generally over the north temperate zone. To test the possibility thus advanced that solar changes occur which govern weather, we began to make day-to-day observations of the solar constant at Mount Wilson Observatory in the year 1905. These continued during the summer and autumn months until 1920 . The results, which treat of solar variation, of the transparency of the atmosphere, of the quantity of its precipitable water, of the coolness of sunspots, of the brightness of the sky by day and by night, of the distribution of solar radiation in the different wave-lengths of the spectrum, of the distribution of radiation over the sun's disk, and which involved the invention of various instruments, including the silver-disk, water-stir, and water-flow pyrheliometers for measuring solar radiation in standard units, the pyranometer for measuring the brightness of the sky, the automatic recording balloon pyrheliometer, and others, are described in volumes 2, 3 and 4 of the Annals of the Astrophysical Observatory of the Smithsonian Institution. During these Mount Wilson years, I made expeditions to Mount Whitney, 14,500 ft. in altitude, and to Bassour, Algeria, to test whether similar results on the solar constant of radiation are found simultaneously at stations of different altitude and far separated. Also, in 1913 and 1914, automatic recording pyrheliometers were raised by sounding balloons. The most successful flight reached 25,000 metres, and brought back records which closely agreed with solar constant values obtained at Mount Wilson and our other stations.

Up to 1919 our observations of the solar constant had all been made by the fundamental method of Langley. Briefly, it consists in measures of the intensity of sun rays at the station, supplemented by spectrobolometric determinations of the distribution of intensity in the solar spectrum. Both types of measurement were made simultaneously, and repeated about five times daily, beginning when the sun is not more than an hour high, and continuing until it approaches maximum elevation. After correcting for instrumental losses, the area included under the bolographic curve of the spectrum is corrected to be proportional to the pyrheliometer measurement of the total solar beam intensity. Then, by computation, each part of the spectral curve is raised to the intensity it would have outside the atmosphere. Then the area included under this computed extra-atmospheric curve, divided by the area of the corrected observed curve, is the multiplier to increase the pyrheliometer reading to what it would be outside the atmosphere. After reducing this to mean solar distance, we have the solar constant of radiation.

With the long computation involved, usually but one determination could be made by this method per day. Its accuracy, apart from instrumental and computing errors, depended on perfect uniformity of the transparency of the atmosphere for several hours. If the sky was clearing up, the result was too high; if growing hazy, the result was too low.

With these drawbacks, it is not remarkable that many meteorologists were not convinced that our results indicating solar variability were sound. They were inclined to think them merely accidental consequences of imperfect observation, or imperfectly uniform sky. Mr. H. H. Clayton, however, who has deserved specially well of meteorologists as editor of "World Weather Records", was at that time chief forecaster of the Argentine. He became convinced by Mount Wilson solar constant work, not only that the sun is really variable, but also that its variations are of first-rate consequence for meteorology.

To show the reasonableness of his views, I may remind readers that the accidental error of a mean diminishes with the square root of the number of observations. Mr. Clayton made use of this 
principle. He collected all the solar constant values of the years 1913,1914, 1915, and 1918, and placed them in six groups ranging from 1.89 to 2.01 calories, of which I abstract the highest and lowest as follows : presence of volcanic dust, or some other unusual atmospheric condition might affect it, we have frequently checked its results by employing the fundamental method of Langley.

Now I come to state the outstanding results of

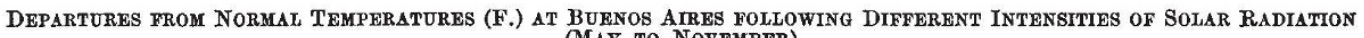
(MAY TO NOVEMBER)

\begin{tabular}{|c|c|c|c|c|c|c|c|c|c|c|c|c|c|c|c|c|c|}
\hline \multirow{2}{*}{$\begin{array}{c}\text { Solar } \\
\text { Constant } \\
\text { (Cal. per min.) }\end{array}$} & \multirow{2}{*}{$\begin{array}{c}\text { Number } \\
\text { of Days } \\
\text { Observed }\end{array}$} & \multicolumn{16}{|c|}{ Days after Solar Observation } \\
\hline & & 0 & 1 & 2 & 3 & 4 & 5 & 6 & 7 & 8 & 9 & 10 & 11 & 12 & 13 & 14 & 15 \\
\hline $\begin{array}{l}2.00 \pm 0.01 \\
1.90 \pm 0.01\end{array}$ & $\begin{array}{l}29 \\
30\end{array}$ & $\begin{array}{l}-2 \cdot 2 \\
+1 \cdot 8\end{array}$ & $\begin{array}{l}-1 \cdot 3 \\
+1 \cdot 8\end{array}$ & $\begin{array}{l}-0.9 \\
+4.1\end{array}$ & $\begin{array}{l}-1 \cdot 4 \\
+2 \cdot 3\end{array}$ & $\begin{array}{l}-1 \cdot 3 \\
-1 \cdot 6\end{array}$ & $\begin{array}{l}-0.4 \\
-1.8\end{array}$ & $\begin{array}{l}-0.4 \\
-1.8\end{array}$ & $\begin{array}{l}+0 \cdot 5 \\
-2 \cdot 7\end{array}$ & $\begin{array}{l}+2 \cdot 7 \\
-1.4\end{array}$ & $\begin{array}{l}+2.9 \\
-0.9\end{array}$ & $\begin{array}{l}+3 \cdot 6 \\
-2 \cdot 5\end{array}$ & $\begin{array}{l}+2.5 \\
-0.9\end{array}$ & $\begin{array}{l}-0.2 \\
+0.2\end{array}$ & $\begin{array}{l}+0.2 \\
-0.5\end{array}$ & $\begin{array}{l}+0.4 \\
+0.4\end{array}$ & $\begin{array}{l}+1.1 \\
-0.5\end{array}$ \\
\hline
\end{tabular}

The opposite trend of these values of temperature departures is obvious. Of sixteen pairs of values just given, the signs of twelve pairs are opposite. As the numbers of observations are so large, the accidental error of the mean values, approximately 2.00 and 1.90 calories, respectively, is only about one fifth as great as the average accidental error of the individual days. Hence the probability that we deal here actually with well-separated levels of solar radiation is strong. The marked opposition of the average marches of temperature departures, following the contrasted observing dates, certainly gives definite significance to these dates, and if it be not the variation of the sun, it is at least something of forecasting value.

These and other meteorological applications of Clayton's led us to wish to improve and render more continuous our solar constant programme. In 1918, therefore, we established .a solar station at Calama in the nitrate desert of Chile, at a level of about $6,000 \mathrm{ft}$. From that time to the present we have endeavoured, so far as possible, to make one or more solar constant determinations on every fair day. While most of this work has been supported by the United States Government, large sums in aid have come from the income of the Hodgkins Fund of the Smithsonian Institution, from Mr. John A. Roebling, and from the National Geographic Society. At present we operate three observing stations: Montezuma, near Calama, Chile, altitude 9,000 ft. ; Table Mountain, Southern California, altitude 7,500 ft. ; Tyrone Station on Burro Mountain, New Mexico, altitude 8,000 ft.

In 1919 we noticed that the coefficients of atmospheric transmission for all wave-lengths of radiation could be empirically represented, to an excellent approximation, as specific functions of the brightness of the sky near the sun. This enabled us to multiply observations of the solar constant daily as the measurements were quickly made. Also, as the sky brightness could be almost instantaneously determined, the new method avoided errors due to changes in atmospheric transparency. In all recent years we have preferred this empirical 'new method', but fearing that this long-continued daily recording of the intensity of the solar radiation. Solar variations are small but real. We may assign as the average amplitude for one combined rise and fall of the solar constant, 0.7 per cent. Such variations as this may be expected to occur about once in twenty days. That is, we may expect annually about twenty cases of rise and twenty cases of fall to give wellmarked sequences of solar change averaging 0.7 per cent, and extending from three to six days during such a sequence. Rarely, however, solar changes of several times this amplitude may occur.

In order to set out the evidence quite clearly, I will refer to results published in a paper of mine three years ago. Having searched the record for the 12-year interval 1924-1935, I found 320 wellmarked cases of solar change, about half of rise and half of fall. I divided these into monthly groups, so that there were about fourteen cases of each kind per month on the average. Some good months had as many as twenty, and only one test, that of falling radiation in February, was represented by less than ten dates.

For each of the 320 dates, I computed the departures from normal temperature at Washington and at three other cities for 16 days following the supposed solar change. Recalling that there were from ten to twenty cases of each kind for each month, it will be seen that by taking the mean results, I obtained fairly strong representations of the average march of departure from normal temperature which follows in each month of the year at Washington and at the other places, after a sequence of rise or of fall of solar radiation is observed to begin.

In every month these average marches of temperature departures showed opposite trends following, respectively, observed rise and observed fall of solar radiation. It would be more striking to show here a plot covering all months, but I content myself, in illustration, with giving merely the figures for October at Washington. Interested readers may plot them. The figures are adjusted to give zero average temperature departure after both rising and falling radiation, by adding 
appropriate constants throughout to each of the lines of departures as originally computed. A third line gives the deviations which would be found if a curve representing 'falling' departures were folded over upon a curve representing 'rising' ones. able conclusion than this. Solar changes exist, and are factors of prime importance governing day-to-day weather changes. Apparently if the sun's changes could be observed with accuracy from day to day, meteorologists would receive a new and important element, which might probably

The Average Trends of October Temperature Departures (F.) Following, for 16 Days Ruspectively, Rising and Faling Solar

\begin{tabular}{|l|rrrrrrrrrrrrrrrrrr}
\hline Days after & 0 & 1 & 2 & 3 & 4 & 5 & 6 & 7 & 8 & 9 & 10 & 11 & 12 & 13 & 14 & 15 & 16 & \multicolumn{10}{c|}{ RADIATION } \\
\hline Rising & $-1 \cdot 0$ & $-2 \cdot 6$ & $-3 \cdot 0$ & $-1 \cdot 6$ & $0 \cdot 8$ & $0 \cdot 3$ & $0 \cdot 8$ & $4 \cdot 9$ & $6 \cdot 5$ & $5 \cdot 3$ & $1 \cdot 4$ & $-0 \cdot 7$ & $-1 \cdot 5$ & $0 \cdot 3$ & $-1 \cdot 4$ & $-5 \cdot 2$ & $-3 \cdot 7$ \\
\hline Falling & $2 \cdot 2$ & $1 \cdot 9$ & $1 \cdot 2$ & $-0 \cdot 6$ & $-0 \cdot 7$ & $1 \cdot 9$ & $-2 \cdot 1$ & $-4 \cdot 6$ & $-4 \cdot 8$ & $-3 \cdot 8$ & $-2 \cdot 7$ & $2 \cdot 0$ & $0 \cdot 0$ & $0 \cdot 0$ & $0 \cdot 8$ & $4 \cdot 0$ & $5 \cdot 9$ \\
\hline Folded discrepancy & $+1 \cdot 2$ & $-0 \cdot 7$ & $-1 \cdot 8$ & $-2 \cdot 2$ & $+0 \cdot 1$ & $+2 \cdot 2$ & $-1 \cdot 3$ & $+0 \cdot 3$ & $+1 \cdot 7$ & $+1 \cdot 5$ & $-1 \cdot 3$ & $+1 \cdot 3$ & $-1 \cdot 5$ & $+0 \cdot 3$ & $-0 \cdot 6$ & $-1 \cdot 2$ & $+2 \cdot 2$ \\
\hline
\end{tabular}

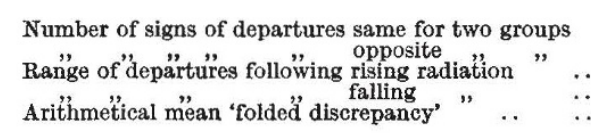

The range of temperature is so large that it is difficult to accept the conclusion that so great an effect is really caused by radiation changes of the order of 0.7 per cent. Hence $I$ have tested the result in several ways. First, as shown in my paper, when comparing the earlier with the later years, the curves are very similar for the years 1924-30, as compared to the years 1931-35. Secondly, selecting 46 cases of unusually large change in the observed solar radiation, I found them followed on the average by temperature departures exhibiting features the same in phase, but of about twice the average amplitude, of those following usual observed solar changes. Thirdly, and most telling of all, I considered time next preceding each of the 320 selected dates. I computed for each of these cases the temperature departures of the preceding 16 days. Then $I$ determined correlation coefficients between the march of temperatures for 16 days preceding and for 16 days following the cases of rising solar radiation and the cases of falling solar radiation. The result was highly significant, and is as follows:

Prior to solar change, $r=+11 \pm 6$ per cent. After solar change, $\quad r=-54 \pm 5$ per cent.

Thus there is no significant correlation of the trends of temperature for 16 days preceding rising and falling sequences of observed solar radiation, but after the solar change there is a negative correlation coefficient eleven times its probable error. Evidently the 320 dates were significant; but they were selected only because observation indicated that rise or fall in solar radiation began with them.

Similar results as regards opposition of trends and magnitude of their separations are found at each of the four temperature stations selected in different parts of the world. The effects are large, ranging from $10^{\circ}$ to $20^{\circ} \mathrm{F}$. I see no other reason- enable them to predict details of weather for two weeks in advance. To attain the necessary accuracy and continuity of solar observation would require, I think, ten stations on high mountains in desert lands.

Long-range solar variations are also interesting. When we take monthly mean values, their accidental errors are reduced on the average by more than fourfold as compared with daily values, because from sixteen to twenty-five daily values enter into each monthly mean. Moreover, our three stations, separated by thousands of miles, agree fairly closely in their indications of the trend of solar variation over many years.

As we scan the curve of solar change since 1920, it appears to be irregular. But I have analysed it, searching for all the regular periodicities which it may contain. I have found twelve of them, ranging from 7 months to 274 months in length, and 274 months proves to be approximately the least common multiple of them all. In the case of half these periodicities, it was possible to derive them independently from two, or even three separate successive intervals, and to show satisfactorily that they persisted in approximately equal phases and amplitudes throughout the total interval of fifteen years. For the longer periods, exceeding thirty months, this check was not available. However, there was still evidence, by comparing individually several successive recurrences, that these longer supposed periodicities repeated in nearly the same phases and amplitudes.

On synthesizing these twelve periodicities, they retraced the observed trend of solar variation from 1920 to 1934 so exactly as to give an average monthly deviation from observation of only $0 \cdot 2$ per cent.

If, now, 274 months, or approximately 23 years, is really a master cycle in the sun, it may well be expected to reveal itself also in weather. It does 
so. As noted by Wild, there is a 23-year periodicity in the temperature of that eity which in his time was called St. Petersburg. Many other meteorologists have noted this cycle in other data. Hale found it in the magnetism of sunspots. The 11-year Wolf sunspot number cycles are of alternating unequal intensity. Tree-ring widths show it. It may even be discovered in the thicknesses of
92 years. These intervals correspond to double and quadruple the 23-year cycle. On this basis one may confidently predict, for example, that the great drought of the past ten years in the western United States is now broken, but will recur in considerable severity beginning 1975, and will recur with the excessive severity of the one just past beginning about 2021 .

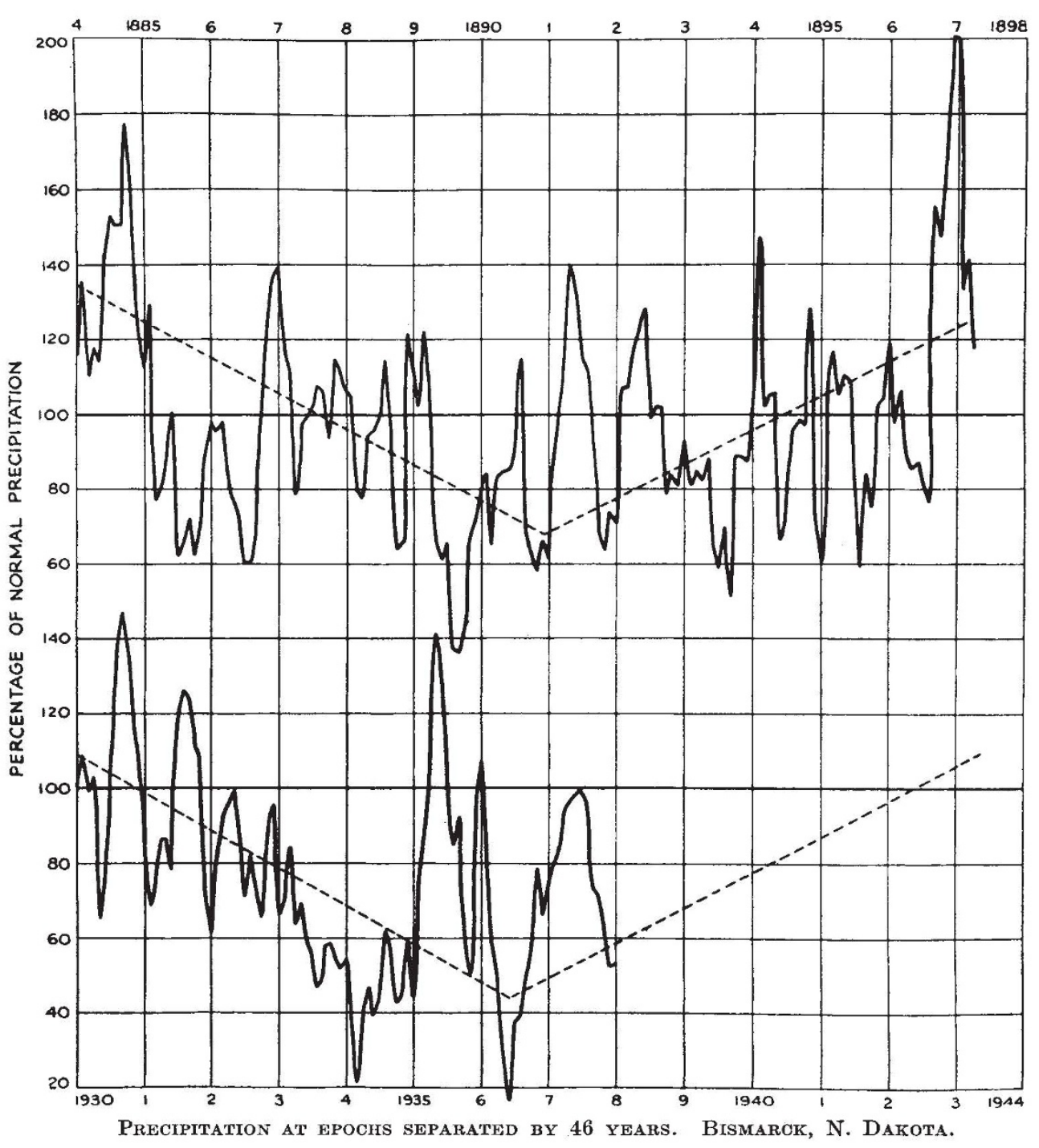

varves deposited by rivers and lakes in former geological ages.

For some stations, and notably for the precipitation, as at Nagpur in India, or at Peoria in Illinois, the principal secular features repeat themselves at intervals of 23 years so unmistakably in approximately equal phases and forms, that predictions based thereon covering years in advance are fairly well verified. More important is the recurrence of severe drought conditions at intervals of 46 years, and recurring still more severely every
In this connexion I will close by quoting from some correspondence of the past five years, illustrated by a graph showing the similarity of precipitation at Bismarck, North Dakota, in recent years, with that of 46 years before.

Under dates of January 1, 1934, January 1, 1935, March 14, 1936, February 6, 1937, and January 4, 1938, a farmer in South Dakota asked me to predict for him in each case a year in advance the trend of precipitation, and sometimes also of temperature. That area has suffered greatly from 
drought in recent years. With strongly expressed cautionary statements as to the insecurity of such predictions, I have given him, year by year, the following indications.

1934: "There will be more precipitation in Minnesota and the Dakotas in 1934 than in 1933, but it will be in the latter half of 1934 that the relief will come."'

1935 : "One could hardly expect normal rainfall in South Dakota in 1935."

1936 : "Precipitation far below normal, but with some improvement in the autumn. As regards temperature, the year 1935 followed almost exactly the pattern of temperature 46 years ago, i.e., 1889 . If 1936 should follow 1890, it should show a very cold winter (as indeed has occurred), followed by normal temperature in spring and the early part of the summer."

1937 : "A good precipitation in the spring or early summer of 1937, followed by a dry autumn and winter, recovery in the spring of 1938."
1938 : "Normal precipitation during the first six months of 1938 , with some (but not excessive) letdown for the remainder of the year, and for the first five months of 1939. Then a short dry spell in the middle of 1939 , but precipitation normal or above normal after November 1939 for considerable time."

In January 1938, my correspondent said : "Because of the accuracy of your former predictions of weather conditions for the Dakotas, I am again soliciting your predictions for the coming season. I have much confidence in your ability to predict, therefore please do your best once more."

These forecasts were made by studying the departures from normal conditions at Bismarck, North Dakota, 46 years previously. How well they were fulfilled is to be estimated by examining the accompanying graph.

\section{Use of Isotopes in Biology}

$\mathrm{T}^{\mathrm{H}}$ HE discovery both of artificial radioactive elements and heavy non-radioactive isotopes, together with methods of concentration of the latter, has opened up new methods of examining the reactions and movements of substances in the body.

The isotopic indicator most frequently used in biological research is radioactive phosphorus $\left({ }^{32} \mathrm{P}\right)$ which may be prepared by the bombardment of carbon disulphide by neutrons from a radiumberyllium source. The sulphur atom takes up a neutron and gives out a proton, forming heavy, unstable, radioactive phosphorus (half-life period 14 days) :

$$
{ }_{16}^{32} \mathrm{~S}+{ }_{0}^{1} n \rightarrow{ }_{15}^{32} \mathrm{P}+{ }_{1}^{1} \mathrm{H} \text {. }
$$

The phosphorus is then oxidized to phosphate. Stronger preparations may be obtained by bombarding red phosphorus with deuterium ions using a cyclotron :

$$
{ }_{15}^{31} \mathrm{P}+{ }_{1}^{2} \mathrm{D} \rightarrow{ }_{15}^{32} \mathrm{P}+{ }_{1}^{1} \mathrm{H} .
$$

For use, a small amount of the labelled sodium phosphate is added to ordinary sodium phosphate solution, and by this means the path of the phosphorus in the body can be traced. Estimations are carried out by observing the decay, at a given time, using a Geiger counter, and comparing directly with the decay of a similar standard at the same time, thus avoiding corrections for the rate of decay due to lapse of time. Thus if it is desired to determine the radioactive phosphorus content of the bone of an animal to which a labelled phosphate solution has been administered (and hence determine any exchange in the phosphate of the bone), a known weight of bone ash from the animal is placed under the Geiger counter and the strength observed. This is compared directly with the same weight of calcium phosphate, precipitated together with the labelled phosphate from a known weight of solution. This method has placed an extremely delicate method of estimation in the hands of the experimenter and has the great advantage that it is not necessary to purify the substance carefully from nonradioactive elements.

of the non-radioactive elements, deuterium $\left({ }^{2} \mathrm{H}\right)$ has been isolated in a state of purity; while heavy oxygen $\left({ }^{18} \mathrm{O}\right)$ and heavy nitrogen $\left({ }^{15} \mathrm{~N}\right)$ have been concentrated sufficiently to make their use as indicators possible.

Heavy hydrogen and oxygen may be accurately estimated by conversion to water, and, after careful purification, determination of the density of the latter. Heavy nitrogen is determined by the mass-spectrograph. This method may also be used for the determination of heavy oxygen: it has the advantage that very careful purification is unnecessary.

It may be objected that the use of isotopes as indicators in the living body may disturb the normal conditions. Actually, the proportion of radioactive phosphorus which it is necessary to use is extremely small, and the radiation from it may be comparable with that from the potassium which is already present in the body, and on decaying it is converted to a sulphur atom. Heavy 